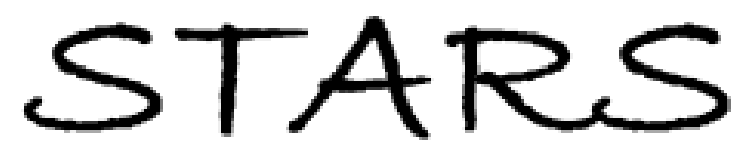

University of Central Florida

STARS

$1-1-2015$

\title{
Determining origin in a migratory marine vertebrate: a novel method to integrate stable isotopes and satellite tracking
}

\author{
Hannah B. Vander Zanden \\ Anton D. Tucker \\ Kristen M. Hart \\ Margaret M. Lamont \\ David S. Addison
}

See next page for additional authors

Find similar works at: https://stars.library.ucf.edu/facultybib2010

University of Central Florida Libraries http://library.ucf.edu

This Article is brought to you for free and open access by the Faculty Bibliography at STARS. It has been accepted for inclusion in Faculty Bibliography 2010 s by an authorized administrator of STARS. For more information, please contactSTARS@ucf.edu.

\section{Recommended Citation}

Vander Zanden, Hannah B.; Tucker, Anton D.; Hart, Kristen M.; Lamont, Margaret M.; Addison, David S.; Mansfield, Katherine L.; Phillips, Katrina F.; Wunder, Michael B.; Bowen, Gabriel J.; Pajuelo, Mariela; Bolten, Alan B.; and Bjorndal, Karen A., "Determining origin in a migratory marine vertebrate: a novel method to integrate stable isotopes and satellite tracking" (2015). Faculty Bibliography 2010s. 6846.

https://stars.library.ucf.edu/facultybib2010/6846

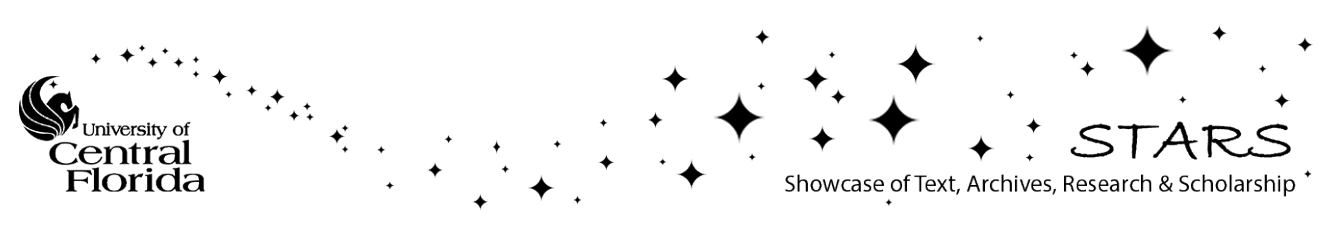




\section{Authors}

Hannah B. Vander Zanden, Anton D. Tucker, Kristen M. Hart, Margaret M. Lamont, David S. Addison,

Katherine L. Mansfield, Katrina F. Phillips, Michael B. Wunder, Gabriel J. Bowen, Mariela Pajuelo, Alan B.

Bolten, and Karen A. Bjorndal 


\title{
Determining origin in a migratory marine vertebrate: a novel method to integrate stable isotopes and satellite tracking
}

\author{
Hannah B. Vander Zanden, ${ }^{1,2,11}$ Anton D. Tucker,${ }^{3}$ Kristen M. Hart, ${ }^{4}$ Margaret M. Lamont, ${ }^{5}$ \\ Ikuko Fujisaki, ${ }^{6}$ David S. Addison, ${ }^{7}$ Katherine L. Mansfield ${ }^{8}$ Katrina F. Phillips, ${ }^{9}$ Michael B. Wunder, ${ }^{10}$ \\ Gabriel J. Bowen, ${ }^{2}$ Mariela Pajuelo, ${ }^{1}$ Alan B. Bolten, ${ }^{1}$ and Karen A. Bjorndal ${ }^{1}$ \\ ${ }^{1}$ Archie Carr Center for Sea Turtle Research and Department of Biology, University of Florida, Gainesville, Florida 32611 USA \\ ${ }^{2}$ Department of Geology and Geophysics, University of Utah, Salt Lake City, Utah 84112 USA \\ ${ }^{3}$ Mote Marine Laboratory, Sarasota, Florida 34236 USA \\ ${ }^{4}$ Southeast Ecological Science Center, U.S. Geological Survey, Davie, Florida 33314 USA \\ ${ }^{5}$ Southeast Ecological Science Center, U.S. Geological Survey, Gainesville, Florida 32653 USA \\ ${ }^{6}$ Ft. Lauderdale Research and Education Center, University of Florida, Davie, Florida 33314 USA \\ ${ }^{7}$ Conservancy of Southwest Florida, Naples, Florida 34102 USA \\ ${ }^{8}$ Department of Biology, University of Central Florida, Orlando, Florida 32816 USA \\ ${ }^{9}$ Rosenstiel School of Marine and Atmospheric Science, University of Miami, Miami, Florida 33149 USA \\ ${ }^{10}$ Department of Integrative Biology, University of Colorado, Denver, Colorado 80217 USA
}

Abstract. Stable isotope analysis is a useful tool to track animal movements in both terrestrial and marine environments. These intrinsic markers are assimilated through the diet and may exhibit spatial gradients as a result of biogeochemical processes at the base of the food web. In the marine environment, maps to predict the spatial distribution of stable isotopes are limited, and thus determining geographic origin has been reliant upon integrating satellite telemetry and stable isotope data. Migratory sea turtles regularly move between foraging and reproductive areas. Whereas most nesting populations can be easily accessed and regularly monitored, little is known about the demographic trends in foraging populations. The purpose of the present study was to examine migration patterns of loggerhead nesting aggregations in the Gulf of Mexico (GoM), where sea turtles have been historically understudied. Two methods of geographic assignment using stable isotope values in known-origin samples from satellite telemetry were compared: (1) a nominal approach through discriminant analysis and (2) a novel continuous-surface approach using bivariate carbon and nitrogen isoscapes (isotopic landscapes) developed for this study. Tissue samples for stable isotope analysis were obtained from 60 satellite-tracked individuals at five nesting beaches within the GoM. Both methodological approaches for assignment resulted in high accuracy of foraging area determination, though each has advantages and disadvantages. The nominal approach is more appropriate when defined boundaries are necessary, but up to $42 \%$ of the individuals could not be considered in this approach. All individuals can be included in the continuous-surface approach, and individual results can be aggregated to identify geographic hotspots of foraging area use, though the accuracy rate was lower than nominal assignment. The methodological validation provides a foundation for future sea turtle studies in the region to inexpensively determine geographic origin for large numbers of untracked individuals. Regular monitoring of sea turtle nesting aggregations with stable isotope sampling can be used to fill critical data gaps regarding habitat use and migration patterns. Probabilistic assignment to origin with isoscapes has not been previously used in the marine environment, but the methods presented here could also be applied to other migratory marine species.

Key words: carbon; Caretta caretta; Gulf of Mexico; isoscapes; loggerhead; migration; nitrogen; satellite telemetry; scute; sea turtle.

\section{INTRODUCTION}

The long-distance migrations made by many marine organisms between reproductive areas and feeding habitats present challenges for biologists and conservationists attempting to understand year-round habitat use and connectivity among populations. For most sea

Manuscript received 26 March 2014; revised 17 July 2014 accepted 24 July 2014; final version received 19 August 2014. Corresponding Editor: P. K. Dayton.

${ }^{11}$ E-mail: h.vanderzanden@utah.edu turtle species, foraging grounds can be separated by hundreds or thousands of kilometers from nesting beaches, and individuals must make regular migrations to reproduce, typically to the region of their birth (Miller 1997). The need to understand these movements has been highlighted by the lack of data to accurately assess sea turtle populations and demographic processes, particularly to understand population-wide patterns, rather than local trends (National Research Council 2010). It is difficult to assess the effects of regional anthropogenic threats when baseline data are unavail- 
able prior to the onset of the threat. The Deepwater Horizon oil spill in the Gulf of Mexico (GoM) in 2010 revealed critical gaps in data for sea turtle populations in the region. Biologists were unable to predict long-term effects of the oil spill on sea turtle populations as a result of the lack of suitable data regarding distributions, habitat use, and movements of sea turtles within the GoM (Bjorndal et al. 2011).

The limited information about migratory marine animal movements can, in part, be attributed to the scarcity of methodological approaches that overcome the logistical constraints of following individuals across vast distances in a largely opaque environment. Sea turtles are easily accessed at the nesting beach, and thus, obtaining information about foraging ground use from nesting females can yield a greater sample size with reduced effort. Satellite tracking devices deployed on sea turtles at the nesting rookery provide information about the migratory corridors as well as the foraging areas used after nesting. Publications using this technique have increased markedly through time (Godley et al. 2008). However, satellite telemetry remains expensive, prohibiting researchers from tracking large numbers of individuals (Hart and Hyrenbach 2009).

Another tool to study marine animal migrations is stable isotope analysis, most commonly with isotopes of carbon and nitrogen (Graham et al. 2010, Ramos and González-Solís 2012, McMahon et al. 2013). These ecogeochemical markers are assimilated through an organism's food sources and therefore reflect trophic patterns (DeNiro and Epstein 1978, 1981). In addition, stable isotope ratios can reflect the location where an animal forages and are useful to track movements of marine organisms as a result of spatial gradients in the isotope values of primary producers in the marine environment that are transferred through the food web. The geographic variability in carbon stable isotope ratios $\left(\delta^{13} \mathrm{C}\right)$ within marine phytoplankton is driven primarily by temperature, which affects growth rates, dissolved $\mathrm{CO}_{2}$ concentrations, and rates of $\mathrm{CO}_{2}$ uptake (Goericke and Fry 1994, Hinga et al. 1994, Gruber et al. 1999). Differences in nitrogen stable isotope ratios $\left(\delta^{15} \mathrm{~N}\right)$ in marine primary producers are mainly a result of differential use of nitrogen sources and the biological processes that dominate the movement of nitrogen through the marine ecosystem such as $\mathrm{N}_{2}$-fixation, denitrification, and, to some degree, nitrification (Montoya 2007).

For sea turtles, stable isotope analysis has been employed to examine both diet through various life stages (Reich et al. 2007, Cardona et al. 2009, Lemons et al. 2011, González Carman et al. 2014, Williams et al. 2014) as well as foraging area use within nesting aggregations (Hatase et al. 2002, 2006, Zbinden et al. 2011, Ceriani et al. 2012, Eder et al. 2012, Pajuelo et al. 2012, Seminoff et al. 2012, Tucker et al. 2014, Vander Zanden et al. 2014a). Determining the foraging area of a sea turtle sampled at the nesting beach relies on knowledge regarding the spatial distributions of isotopic values in the potential foraging grounds, yet large-scale isotopic maps have been very limited for the oceans thus far (Graham et al. 2010, Somes et al. 2010, McMahon et al. 2013). Instead, sea turtle isotope values have been related to geographic location with satellite telemetry and stable isotope sampling to characterize the regions that are isotopically distinct (e.g., Pajuelo et al. 2012, Seminoff et al. 2012). After these relationships have been validated, stable isotope analysis alone can be applied to a large number of individuals to determine their foraging areas.

Previous satellite tracking studies of loggerheads in the GoM have revealed that post-nesting females migrate to several different foraging regions within the GoM and greater Caribbean (Hart et al. 2012, Foley et al. 2013, 2014, Tucker et al. 2014). While loggerheads may consume a variety of benthic invertebrates (Dodd 1988), variation in their isotopic values appears to be influenced by foraging area more than diet (Pajuelo et al. 2012, Tucker et al. 2014). Therefore, the purpose of this study was to determine if significant spatial structure in the isotopic values of loggerheads in and around the GoM facilitates the use of $\delta^{13} \mathrm{C}$ and $\delta^{15} \mathrm{~N}$ values to assess foraging area origin of nesting individuals. Samples of scute tissue covering the carapace were obtained from 60 satellite-tracked individuals at five nesting beaches from within the GoM. We tested two methods of assignment consisting of a nominal approach that requires an a priori definition of potential foraging areas that has previously been used in the Northwest Atlantic (Ceriani et al. 2012, Pajuelo et al. 2012, Vander Zanden et al. 2014a) as well as a novel, continuous-surface approach. We tested the accuracy of each method through calibration and validation data sets and examined whether the inclusion of a prior probability distribution from all satellite tracking records from the nesting beach can improve assignment accuracy. Based on the regional stable isotopic differences that have previously been identified for loggerheads in the GoM (Tucker et al. 2014), we predicted that the continuous-surface approach would be a more effective tool than nominal assignment for determining foraging area use of nesting females in the region.

Both the nominal and continuous-surface assignments are likelihood-based approaches and rely on characterizing the geographic distribution of isotope values in the foraging areas (Wunder 2012). The nominal approach requires the use of predefined geographic regions for which isotope distributions are estimated and used to compute probabilities of membership. The continuoussurface approach incorporates predictive models of isotope-landscapes, or isoscapes, that depict the geographic patterning of stable isotope values by using measurements at known locations to spatially interpolate values at locations without measurements (West et al. 2010). Isoscape models are combined with estimates 
TABLE 1. Collection year and total number of samples collected from nesting loggerheads in the Gulf of Mexico during the sampling period.

\begin{tabular}{lc}
\hline \hline \multicolumn{1}{c}{ Nesting beach and year } & Samples collected \\
\hline Eglin Air Force Base (EAFB) & 2 \\
2012 & \\
St. Joseph Peninsula (SJP) & 2 \\
2011 & 4 \\
2012 & \\
Casey Key (CK) & 22 \\
2011 & 8 \\
2012 & 5 \\
Keewaydin Island (KI) & \\
2012 & 17 \\
Dry Tortugas (DRTO) & \\
2012 & 60 \\
All sites & \\
$2011-2012$ & \\
\end{tabular}

of model uncertainty and biologically based variance in isotope values to compute spatially explicit probabilities of origin across the isoscape (Wunder 2010). This approach has been commonly employed to understand migratory connectivity of terrestrial species based on the predictable, continent-wide gradients in $\delta^{2} \mathrm{H}$ and $\delta^{18} \mathrm{O}$ values of precipitation that are incorporated into an animal's tissue through the food web (Hobson et al. 2010). These isoscapes were characterized at the global scale for the terrestrial environment (Bowen et al. 2005) and have been extensively applied to determine origin of migratory species, including butterflies, birds, and bats (Hobson and Wassenaar 2008).

However, equivalent isoscapes do not exist for the marine environment. While $\delta^{13} \mathrm{C}$ and $\delta^{15} \mathrm{~N}$ values are known to exhibit spatial variation within ocean basins, the only marine isoscapes that have been produced for the Atlantic region (based on previously published isotopic values in primary producers) are too coarse in the GoM to be used to identify distinct foraging areas (Somes et al. 2010, McMahon et al. 2013). To circumvent this limitation, we created new isoscapes by using the isotopic values of scute tissue from knownorigin individuals to generate loggerhead-specific $\delta^{13} \mathrm{C}$ and $\delta^{15} \mathrm{~N}$ isoscapes.

Our results allow us to assess the reliability of each approach for predicting foraging area origin in untracked turtles for future studies in this region and make recommendations to guide future work. Applying assignment methods in future research can help to identify geographic hotspots of use and monitor foraging aggregation trends in the GoM from the nesting beach. Additionally, increased knowledge about the movements and origins of loggerheads in the GoM allows managers to more accurately predict how anthropogenic threats such as fisheries or petroleum activities can affect loggerhead populations in this region.

\section{Methods \\ Sample collection}

Sea turtle scute is an inert keratinized tissue that covers the bony plates of the carapace. Samples of scute tissue were collected from a total of 60 nesting loggerheads at five nesting beaches on the west coast of Florida in 2011 and 2012: Eglin Air Force Base (EAFB), Saint Joseph Peninsula (SJP), Casey Key (CK), Keewaydin Island (KI), and Dry Tortugas (DRTO) (Table 1). Samples were collected from the posterior medial region of the third right lateral scute with a sterile 6-mm biopsy punch and stored until analysis (see Appendix A). Prior to sampling, the carapace was cleaned with isopropyl alcohol, and the sampling site was avoided in the application of the satellite transmitter. The scute sampling process is noninvasive, as repeated scute sampling does not significantly affect the health or physiological condition of juvenile loggerheads (Bjorndal et al. 2010).

Body size was determined by measuring the curved carapace length from the anterior midpoint of the nuchal scute to the tip of the longer posterior marginal scute at the time of sample collection (Bolten 1999). Satellite transmitters were attached to nesting females after oviposition. The foraging area was determined as the centroid of the home range based on satellite tracking data. Additional details on transmitter attachment and foraging area determination are included in Appendix A.

Scute samples collected at the nesting beach represent the foraging period prior to reproduction, while satellite transmitters attached at the nesting beach track movements after reproduction. Females exhibit consistency in their foraging area use (Broderick et al. 2007, Marcovaldi et al. 2010, Hawkes et al. 2011), and exhibit fidelity to a primary residence area that they occupy $>11$ months of the year (Foley et al. 2014). Therefore, using the most recent layer of scute to assess assignment accuracy based on satellite tracking information is reasonable because the single sample will be indicative of long-term patterns of resource use (Vander Zanden et al. 2010). Reproductive sea turtles are believed to fast during the migration and nesting period (Bonnet et al. 1998, Plot et al. 2013); therefore, the isotopic signal retained in the scute likely reflects assimilation only at the foraging area. The mean period between reproductive seasons, or the remigration interval, ranges from 2.5 to $3.0 \mathrm{yr}$ for loggerheads (Schroeder et al. 2003).

Samples from both years were combined, as little temporal variability was expected for three reasons. First, individual loggerheads exhibit minimal variation in isotopic values over periods of up to $12 \mathrm{yr}$, as recorded in scute layers representing 0.6-yr increments (Vander Zanden et al. 2010). Second, sampling year did not contribute to significant variation in the isotopic values of loggerheads when considered among other factors including location, body size, foraging area depth, and distance to shore (Tucker et al. 2014). Third, top predators act as ecological integrators of environmental change, and 
the tissues of higher trophic level organisms assimilate isotopes over a longer time frame, attenuating the spatial and temporal variability at the base of the food web (O’Reilly et al. 2002, Bump et al. 2007).

\section{Scute preparation and stable isotope processing}

All scute samples were rinsed with deionized water and dried at $60^{\circ} \mathrm{C}$ for $24 \mathrm{~h}$ in the laboratory prior to analysis. Scutes grow via deposition of new keratinized skin directly under the old tissue such that the oldest tissue is found on the dorsal surface of the scute, whereas the youngest tissue is found on the ventral surface (Alibardi 2005). Each scute biopsy was glued ventral side down with the dorsal surface (oldest tissue) exposed, and $50-\mu \mathrm{m}$ layers were obtained using a carbide end mill (Sherline 5100 with digital readout). This interval was selected as the smallest interval that would provide sufficient sample for stable isotope analysis and represents approximately $0.6 \mathrm{yr}$ of resource use in adult loggerhead turtles (Vander Zanden et al. 2010). The complete records will be evaluated in a future study, but only the newest scute layer, representing 0.6 $\mathrm{yr}$ of recent resource use history was used here.

Carbon and nitrogen isotope composition were measured at the Department of Geological Sciences, University of Florida, Gainesville, Florida, USA, using a Carlo Erba NA 1500 CNS elemental analyzer (Thermo Scientific, Waltham, Massachusetts, USA) interfaced via a ConFlo II to a DeltaV Advantage isotope ratio mass spectrometer (Thermo Electron, Waltham, Massachusetts, USA). Sample stable isotope ratios relative to the isotope standard were expressed in the following conventional delta $(\delta)$ notation: $\delta=\left(\left[R_{\mathrm{sam}} /\right.\right.$ $R_{\text {std }}$ - 1) where $R_{\text {sam }}$ and $R_{\text {std }}$ are the corresponding ratios of heavy to light isotopes $\left({ }^{13} \mathrm{C} /{ }^{12} \mathrm{C}\right.$ and $\left.{ }^{15} \mathrm{~N} /{ }^{14} \mathrm{~N}\right)$ in the sample and international standard, respectively. Vienna Pee Dee Belemnite was used as the standard for ${ }^{13} \mathrm{C}$ and atmospheric $\mathrm{N}_{2}$ for ${ }^{15} \mathrm{~N}$. The reference materials USGS40 (L-glutamic acid with isotopic compositions of $\delta^{13} \mathrm{C}=-26.29 \%$ and $\delta^{15} \mathrm{~N}=-4.52 \%$ ) and USGS41 (Lglutamic acid enriched in ${ }^{13} \mathrm{C}$ and ${ }^{15} \mathrm{~N}$ with isotopic compositions of $\delta^{13} \mathrm{C}=37.63 \%$ and $\delta^{15} \mathrm{~N}=47.57 \%$ ) were used to calibrate all results. The standard deviation of USGS40 was $0.09 \%$ for $\delta^{13} \mathrm{C}$ values and $0.14 \%$ for $\delta^{15} \mathrm{~N}$ values ( $n=143$ replicates), and the standard deviation of USGS41 was $0.13 \%$ o for $\delta^{13} \mathrm{C}$ values and $0.52 \%$ for $\delta^{15} \mathrm{~N}$ values ( $n=32$ replicates). Repeated measurements of a laboratory reference material, homogenized loggerhead scute collected from an individual at a different site, were used to examine consistency in a sample with similar isotopic composition to samples in this study. The standard deviation of the laboratory reference material was $0.15 \%$ o for $\delta^{13} \mathrm{C}$ values and $0.22 \%$ for $\delta^{15} \mathrm{~N}$ values ( $n=57$ replicates).

\section{Assignment methods}

Stable isotope data from the newest scute layer were combined with satellite tracking information to evaluate the effectiveness of performing geographic assignments of origin with two different approaches: linear discriminant analysis and bivariate continuous assignment to carbon and nitrogen isoscapes developed in this study. In both cases, the data were randomly divided into calibration and validation data sets, such that the calibration individuals were used to create the model and the validation individuals were used to assess the accuracy of the model by performing the assignment as if the origin was unknown. The complete data set is available in Appendix B.

Nominal assignment.-The nominal assignment approach (linear discriminant analysis) required defining distinct geographic regions of possible origin with corresponding isotopic characterizations of each region (Wunder 2012). Therefore, we defined five coastal areas used by the loggerheads in this study, and the centroid of foraging area use of each of the 60 females was classified into one of these areas. We did not include any foraging areas within oceanic waters $(>200 \mathrm{~m}$ depth), as all foraging centroids were in waters $<200 \mathrm{~m}$ depth, and thus used only neritic, or coastal areas. We did not observe a neritic-oceanic foraging dichotomy as suggested by some studies (Hawkes et al. 2006, Hatase et al. 2010, Eder et al. 2012)

The delineation of foraging areas was intended to maximize isotopic differences among them to improve our ability to distinguish among the well-established regions that have previously been defined based on the physical, oceanographic, and biological characteristics of the marine environment (Antoine 1972, Wilkinson et al. 2009). We refer to these foraging areas as (1) Southern Gulf of Mexico (SGoM), (2) Northern Gulf of Mexico (NGoM), (3) Eastern Gulf of Mexico (EGoM), (4) Subtropical Northwest Atlantic (SNWA), and (5) South Atlantic Bight (SAB) (Fig. 1). These are similar to the regions that have been used in previous studies (Pajuelo et al. 2012, Tucker et al. 2014) with slight variations to the region names and borders. Additional description is contained in Appendix A.

Because only two of the 60 loggerheads used the SAB, this foraging area was excluded from the nominal assignment, leaving 39 calibration individuals and 19 validation individuals. Levene's test was used to examine the homogeneity of variance in $\delta^{13} \mathrm{C}$ and $\delta^{15} \mathrm{~N}$ values among the foraging areas, and MANOVA was used to test if the foraging areas differed in the combined $\delta^{13} \mathrm{C}$ and $\delta^{15} \mathrm{~N}$ values of the calibration individuals before proceeding with the nominal assignment. Because variance among the groups was homogeneous, linear discriminant analysis was employed. ANOVA with posthoc Tukey HSD tests was used to identify significant differences among foraging areas in $\delta^{13} \mathrm{C}$ and $\delta^{15} \mathrm{~N}$ values separately.

Linear discriminant analysis was used to assign the validation individuals to one of the four discrete foraging areas based on the characterizations of the isotope distributions for those locations in the calibration data set. Each foraging area was defined by a probability 
density of the sampling distribution from the calibration, or training, data set. These conditional probabilities were then inverted using Bayes' rule, providing posterior probability distributions over all candidate foraging areas for each of the validation individuals.

Classification of the 19 validation individuals was performed in one of two ways. First, the prior probability was assumed to be uniform over all of the foraging areas, meaning that it was equally likely for each individual to have originated from each of the four foraging areas. Second, we extended the basic linear discrimination model to include nonuniform prior probabilities for the foraging areas. These priors were independently estimated for each nesting beach, and the prior associated with the beach where the individual was sampled was applied. The prior probabilities used were derived from the proportion of all previously tracked individuals from each nesting beach that used each foraging area (Table 2). The number of loggerheads tracked at each beach ranged from 24 to 102. In the cases where individuals were tracked in more than one year, only the first tracking event that resulted in the determination of a putative foraging area was included, so as not to represent individuals more than once. Because satellite-tracking information was only available for two individuals from the EAFB nesting beach, the tracking information from SJP and EAFB were combined due to their proximity, and the same priors were used for individuals from both nesting beaches.

The posterior probability threshold was set at 0.8 , meaning that validation individuals were required to have a 0.8 or greater probability of group membership to be assigned to that foraging area. With four possible foraging areas, this threshold provides a 12-fold improvement over random odds (Wunder 2012). This threshold was used to maintain consistency with other studies that have used similar assignment approaches (Pajuelo et al. 2012, Seminoff et al. 2012). However, we note that it is more difficult to achieve assignments with probability of group membership $\geq 0.8$ with four foraging areas than with two or three foraging areas (e.g., Pajuelo et al. 2012, Vander Zanden et al. 2014a). That is, with four potential foraging areas, maintaining this probability threshold at 0.8 means that we are increasing the odds ratio of likely origin.

The assignment accuracy for individuals in the validation data set was calculated as the percentage of individuals that were assigned to the correct foraging area based on satellite tracking information. We also examined the ability to accurately predict movement in and out of the GoM by considering NGoM, SGoM, and EGoM foraging areas as within the GoM, and the SNWA foraging area to be outside of the GoM.

Continuous-surface assignment.-Isoscapes are predictive models that are created by spatially modeling measured isotope values with a known geographic origin. They can either be created directly from study organism sample tissues or by calibrating an existing spatial model based on isotope values from some other material (Wunder 2012). Here, we use the former approach to make loggerhead keratin-specific isoscapes. The major advantage of creating an isoscape with the organismal tissue values rather than primary producers is that the baseline isotopic values do not have to be converted to animal tissue isotopic values, which can add additional uncertainty to assignments of origin, as it would require information about the isotopic offset between the two.

Geostatistical models can be used to predict stable isotope values at sites where no measurements exist based on the premise of spatial autocorrelation, in which nearby sites will be more closely related than distant sites. GIS-based isoscape surface interpolation models were created with ordinary kriging of the $\delta^{13} \mathrm{C}$ and $\delta^{15} \mathrm{~N}$ values of the 41 calibration individuals using the Geostatistical Analyst extension and geoprocessing tools within ArcGIS version 10 (additional details in Appen$\operatorname{dix} \mathrm{A})$. In this approach, the two individuals from the SAB were included, thus increasing the calibration sample size from the nominal approach.

Assignments were made using both $\delta^{13} \mathrm{C}$ and $\delta^{15} \mathrm{~N}$ values by estimating the likelihood that each raster cell represented the foraging area origin of the validation individuals using a bivariate normal probability function as follows:

$$
\begin{aligned}
f\left(x, y \mid \boldsymbol{\mu}_{i}, \mathbf{\Sigma}\right)= & \frac{1}{\left(2 \pi \sigma_{x} \sigma_{y} \sqrt{1-\rho^{2}}\right)} \\
& \times \exp \left(-\frac{1}{2\left(1-\rho^{2}\right)}\left[\frac{\left(x-\mu_{x}\right)^{2}}{\sigma_{x}^{2}}+\frac{\left(y-\mu_{y}\right)^{2}}{\sigma_{y}^{2}}\right.\right. \\
& \left.\left.+\frac{2 \rho\left(x-\mu_{x}\right)\left(y-\mu_{y}\right)}{\sigma_{x} \sigma_{y}}\right]\right)
\end{aligned}
$$

where $f\left(x, y \mid \boldsymbol{\mu}_{i}, \boldsymbol{\Sigma}\right)$ is the likelihood that an individual with $\delta^{13} \mathrm{C}$ value $=x$ and $\delta^{15} \mathrm{~N}$ value $=y$ originated from cell $i$ with mean $\delta^{13} \mathrm{C}$ and $\delta^{15} \mathrm{~N}$ values equal to the components in the vector $\boldsymbol{\mu}_{i}$ and variance-covariance matrix $\boldsymbol{\Sigma}$, which is decomposed on the right-hand side of the equation such that $\rho$ is the correlation between $\delta^{13} \mathrm{C}$ and $\delta^{15} \mathrm{~N}$ values calculated from the isotopic measurements in the calibration data set, $\sigma_{x}^{2}$ is the pooled error in $\delta^{13} \mathrm{C}$ values, and $\sigma_{y}^{2}$ is the pooled error in the $\delta^{15} \mathrm{~N}$ values. Three error sources were pooled using the equation

$$
\sigma_{\text {pool }}=\sqrt{\sigma_{\mathrm{wn}}^{2}+\sigma_{\mathrm{am}}^{2}+\sigma_{\mathrm{kr}}^{2}}
$$

where $\sigma_{\mathrm{wn}}^{2}$ is the variance associated with isotopic values within individuals, $\sigma_{\mathrm{am}}^{2}$ is the variance associated with isotopic values among individuals at a single foraging site, and $\sigma_{\mathrm{kr}}^{2}$ is the prediction error associated with each point from the krigged surface (c.f. Wunder 2010). The pooled error was calculated independently for each element. The $\sigma_{\text {pool }}$ range was $1.1-3.8 \%$ for $\delta^{13} \mathrm{C}$ values and $1.4-3.4 \%$ o for $\delta^{15} \mathrm{~N}$ values. 

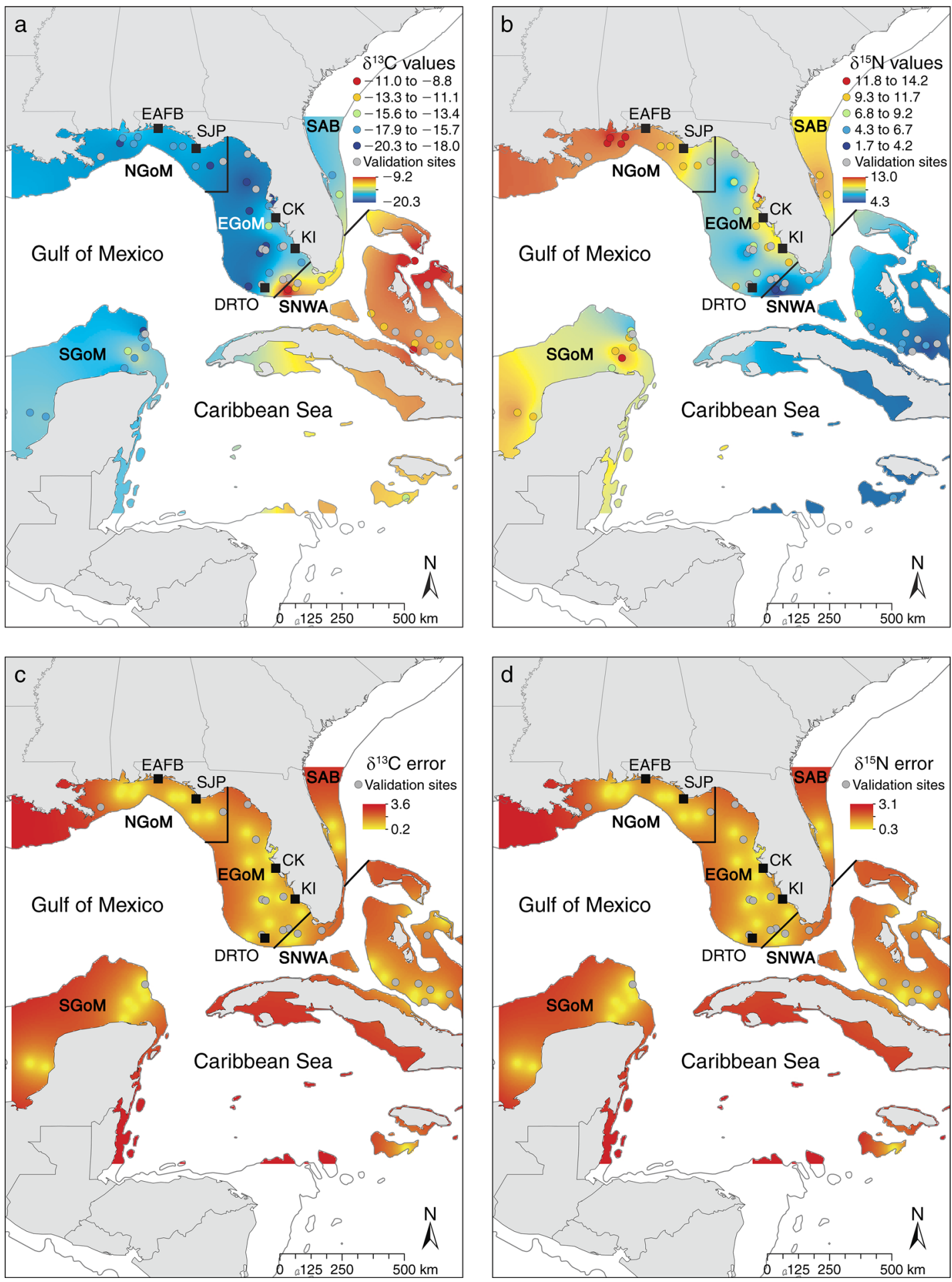

FIG. 1. (a, b) Isoscapes derived from $\delta^{13} \mathrm{C}$ and $\delta^{15} \mathrm{~N}$ values in scute of satellite-tracked loggerheads with the 200-m isobath as a bounding layer. (c, d) Maps of spatial uncertainty (standard deviation) associated with the kriging model. Colored points indicate the foraging area centroid of calibration individuals and stable isotope values, gray points indicate the foraging area location of validation individuals, and black squares indicate the five nesting beaches. Validation individuals were classified to one of five regions in the nominal approach. The combination of predictive surfaces (a, b) along with the kriging error (c, d) and estimates of biological variance (see Methods) was used to determine the origin of the validation individuals in the continuous-surface approach. Nesting beaches are EAFB, Eglin Air Force Base; SJP, St. Joseph Peninsula; CK, Casey Key; KI, Keewaydin Island; DRTO, Dry Tortugas. Foraging areas are SGoM, Southern Gulf of Mexico; NGoM, Northern Gulf of Mexico; EGoM, Eastern Gulf of Mexico; SNWA, Subtropical Northwest Atlantic; SAB, South Atlantic Bight. 
TABLE 2. Proportions of all previous satellite-tracked loggerheads from each of the five nesting beaches that used each of the five foraging areas.

\begin{tabular}{|c|c|c|c|c|}
\hline \multirow[b]{2}{*}{ Foraging areas and assignment type } & \multicolumn{4}{|c|}{ Nesting beaches } \\
\hline & $\mathrm{EAFB} / \mathrm{SJP}^{1-4}$ & $\mathrm{CK}^{2,5-7}$ & $\mathrm{KI}^{8,9}$ & DRTO $^{3,10}$ \\
\hline \multicolumn{5}{|l|}{ EGoM } \\
\hline Nominal & 0.519 & 0.461 & 0.583 & 0.151 \\
\hline Continuous surface & 0.519 & 0.448 & 0.583 & 0.143 \\
\hline \multicolumn{5}{|l|}{ NGoM } \\
\hline Nominal & 0.148 & 0.069 & 0.083 & 0.061 \\
\hline Continuous surface & 0.148 & 0.067 & 0.083 & 0.057 \\
\hline \multicolumn{5}{|l|}{ SGoM } \\
\hline Nominal & 0.333 & 0.196 & 0.042 & 0.061 \\
\hline Continuous surface & 0.333 & 0.19 & 0.042 & 0.057 \\
\hline \multicolumn{5}{|l|}{ SNWA } \\
\hline Nominal & 0 & 0.275 & 0.292 & 0.727 \\
\hline Continuous surface & 0 & 0.267 & 0.292 & 0.686 \\
\hline \multicolumn{5}{|l|}{ SAB } \\
\hline Nominal & & & & \\
\hline Continuous surface & 0 & 0.029 & 0 & 0.057 \\
\hline \multicolumn{5}{|l|}{ Total number of individuals } \\
\hline Nominal & 27 & 102 & 24 & 33 \\
\hline Continuous surface & 27 & 105 & 24 & 35 \\
\hline
\end{tabular}

Notes: The proportions were used to create nonuniform prior probabilities. The value in the top row of the cell indicates the prior probabilities used in nominal assignment, while the bottom row indicates the prior probabilities used in continuous-surface assignment. (The SAB foraging area was not included in the nominal assignments.) The total number of satellite-tracked loggerheads from which these proportions were calculated is also reported. Because only two individuals have been tracked from EAFB, these individuals were combined with the SJP nesting individuals due to the close proximity of these nesting beaches. Data sources are indicated with superscript numbers. Foraging areas are EGoM, Eastern Gulf of Mexico; NGoM, Northern Gulf of Mexico; SGoM, Southern Gulf of Mexico; SNWA, Subtropical Northwest Atlantic; SAB, South Atlantic Bight. Nesting beaches are EAFB/SJP, Eglin Air Force Base/St. Joseph Peninsula; CK, Casey Key; KI, Keewaydin Island; DRTO, Dry Tortugas.

Sources: 1, Foley et al. (2013); 2, Hart et al. (2012); 3, Hart et al. (2014); 4, M. M. Lamont, K. M. Hart, I. Fujisaki, A. R. Sartain, and B. S. Stephens, unpublished data; 5, Girard et al. (2009); 6, Hardy et al. 2014; 7, Tucker et al. (2014); 8, Phillips (2011); 9, K. F. Phillips, K. L. Mansfield, and D. S. Addison, unpublished data; 10, K. M. Hart, unpublished data.

Single values were used for $\sigma_{\mathrm{wn}}^{2}$ to represent the variance observed in individual scute records from the entire scute samples. All layers of the scute samples for each individual were analyzed for a separate study (H. B. Vander Zanden, unpublished data), and the mean of the individual variances was calculated to determine intra-individual variability $\left(\delta^{13} \mathrm{C} \sigma_{\mathrm{wn}}^{2}=0.21 \%\right.$, and $\delta^{15} \mathrm{~N}$ $\sigma_{\mathrm{wn}}^{2}=0.11 \%$ ).

Single values were also used for $\sigma_{\mathrm{am}}^{2}$ to represent the inter-individual variance observed in 15 adult loggerheads sampled in a small foraging site $<5 \mathrm{~km}^{2}$ in size in Florida Bay, Florida in 2011 (Pajuelo et al. 2012). Loggerheads feed on a variety of benthic invertebrates (Dodd 1988), and this term accounts for potential differences in diet among individuals within a limited area. Even when individuals have the same diet, there may be some level of inherent variation as a result of physiological differences among individuals (Vander Zanden et al. 2012) that is also reflected in this term. Our estimate of $\sigma_{\mathrm{am}}^{2}\left(\delta^{13} \mathrm{C} \sigma_{\mathrm{am}}^{2}=1.02 \%\right.$, and $\delta^{15} \mathrm{~N} \sigma_{\mathrm{am}}^{2}=$ $1.82 \%$ ) was derived from epidermis rather than scute, but there is a significant correlation between the isotopic values in the two tissues (H. B. Vander Zanden, unpublished data).

The error associated with the kriging process $\left(\sigma_{\mathrm{kr}}^{2}\right)$ was extracted from a raster map generated with the Geostatistical Analyst extension representing the standard deviation of the kriging prediction (Fig. 1c and d). This model-based component of the error term is a function of the location of the calibration points, such that it is low in close proximity to points with known values and increases with distance from those locations.

As with the nominal assignment process, two types of prior assumptions were used in the continuous-surface assignment. First, the prior probability was assumed to be uniform over all of the cells in the isoscape domain, meaning that it was equally likely for each individual to have originated from any cell in the raster domain. Second, nonuniform prior probabilities that were specific to the nesting beach where the individual was sampled were applied. To do this, we created regionalized raster maps using the same borders as in the nominal assignment approach. The prior probabilities 
included SAB as a fifth foraging area, thus these values were slightly different from those used in the nominal assignment (Table 2). The prior probability raster was then multiplied by the raster produced from the bivariate normal probability function to obtain the posterior probability density surface.

For ease of comparison between individuals, each assignment surface was rescaled to the highest likelihood value from the posterior probability distribution so that all resulting surfaces were composed of relative likelihood values that ranged from 0 to 1 . To assess accuracy, we selected a threshold to recode the cells as "likely" or "unlikely" foraging locations, by assigning cells that were in the upper $25 \%$ of the probability distribution as likely and all other cells as unlikely. Accuracy was calculated as the proportion of the validation locations contained within the posterior density surface at our selected threshold (Vander Zanden et al. 2014c). This metric evaluates the ability to correctly predict a surface that includes the known location of the validation individuals. We also evaluated the accuracy over a range of thresholds from 0.01 to 0.99 at 0.01 increments to explore the effect of selecting a different threshold.

Some studies have used the relative likelihood values to establish thresholds for creating binary maps to demonstrate likely origins of unknown individuals (Hobson et al. 2009, Flockhart et al. 2013, Rushing et al. 2013), while others have used a portion of the posterior probability surface as we have done here (Knick et al. 2014). The posterior probability distributions in our study were often narrow and peaked, and using a threshold based on a relative likelihood resulted in a selection of a very small proportion of the surface and low accuracy. Therefore, using a relative likelihood threshold was not appropriate for our study. One advantage of using a portion of the posterior probability distribution is that the same number of cells or same total area is designated as likely between individual assignments, or one-fourth of the study domain, in this case. The four foraging areas defined in the nominal assignment also encompass approximately one-fourth of the study domain, though they were not exactly equal in area. Therefore, the likely binary assignment regions in the continuous surface approach comprise similarly sized regions as those considered in the nominal approach. To provide summary plots of all validation assignments, the binary maps were summed for all 19 individuals.

All statistics were evaluated using $\mathrm{R}$ version 3.0.2 with $\alpha=0.05$ (R Development Core Team 2013).

\section{RESUlts}

\section{Nominal assignment}

The curved carapace length of female loggerheads in this study ranged from $80.9-116.0 \mathrm{~cm}$. The combined $\delta^{13} \mathrm{C}$ and $\delta^{15} \mathrm{~N}$ values in the most recent layers of loggerhead scute varied significantly among the four foraging areas used by the 39 calibration individuals
(MANOVA, $F_{6,70}=16.29, P<0.001$, Fig. 2a). Post hoc Tukey HSD tests indicated that $\delta^{13} \mathrm{C}$ values in the NGoM were not significantly different from the EGoM or SGoM, whereas $\delta^{15} \mathrm{~N}$ values were not significantly different between the EGoM and SGoM (Table 3). All comparisons between the SNWA and foraging grounds in the GoM were significantly different in both $\delta^{13} \mathrm{C}$ and $\delta^{15} \mathrm{~N}$ values (Table 3), therefore the discriminant analysis had the most power to delineate foraging area origins in or out of the GoM.

The calibration individuals were used as training data in the discriminant analysis to define probability densities before assigning validation individuals. The 19 validation individuals were used to assess the accuracy of using discriminant analysis with two types of priors (uniform and nonuniform, Table 4). With uniform priors, $58 \%$ of the individuals could be assigned to a putative foraging area with a probability of group membership $\geq 0.8$ and the accuracy was $82 \%$ ( 9 of 11 individuals that met the probability threshold were assigned correctly, Fig. 2b). Classification accuracy to one of two groups in or out of the GoM was $91 \%$ (10 of 11 individuals were assigned correctly).

Nesting beach-specific priors were based on the proportions of individuals using each foraging area determined from previous satellite tracking studies (Table 2). For loggerheads nesting in EAFB, SJP, CK, $\mathrm{KI}$, the majority of turtles used waters in the EGoM. At the southernmost beach (DRTO), the majority of nesting loggerheads used waters in the SNWA. At the most northern beaches (EAFB and SJP), all nesting loggerheads used foraging areas within the GoM. With the inclusion of nonuniform priors in the nominal assignments, the portion of individuals that met the threshold for assignment increased to $68 \%$, and assignment accuracy increased to $100 \%$ (13 of 13 individuals that met the probability threshold were assigned correctly, Fig. 2c). Additionally, assignment accuracy to foraging areas in or out of the GoM increased to $100 \%$ (Table 4).

\section{Continuous-surface assignment}

Loggerhead-specific isoscapes (Fig. 1) were created, and a bivariate approach was used to determine the likelihood of origin from each raster cell using $\delta^{13} \mathrm{C}$ and $\delta^{15} \mathrm{~N}$ isoscapes. Assignment results are depicted as raster maps (Appendix C, Figs. C1-C4). The continuoussurface approach differed from the nominal approach, such that predefined foraging area boundaries were not required to make the assignments; however they were necessary to create nonuniform priors. With uniform priors, we found that using a threshold to define the lower $75 \%$ of the surface as "unlikely" resulted in an accuracy level of $79 \%$ (Fig. 3, Table 4). If the accuracy evaluation was restricted to the 11 individuals that resulted in a putative assignment using the nominal approach, the accuracy was $82 \%$ (9 of 11 individuals were assigned accurately). Because we did not use 

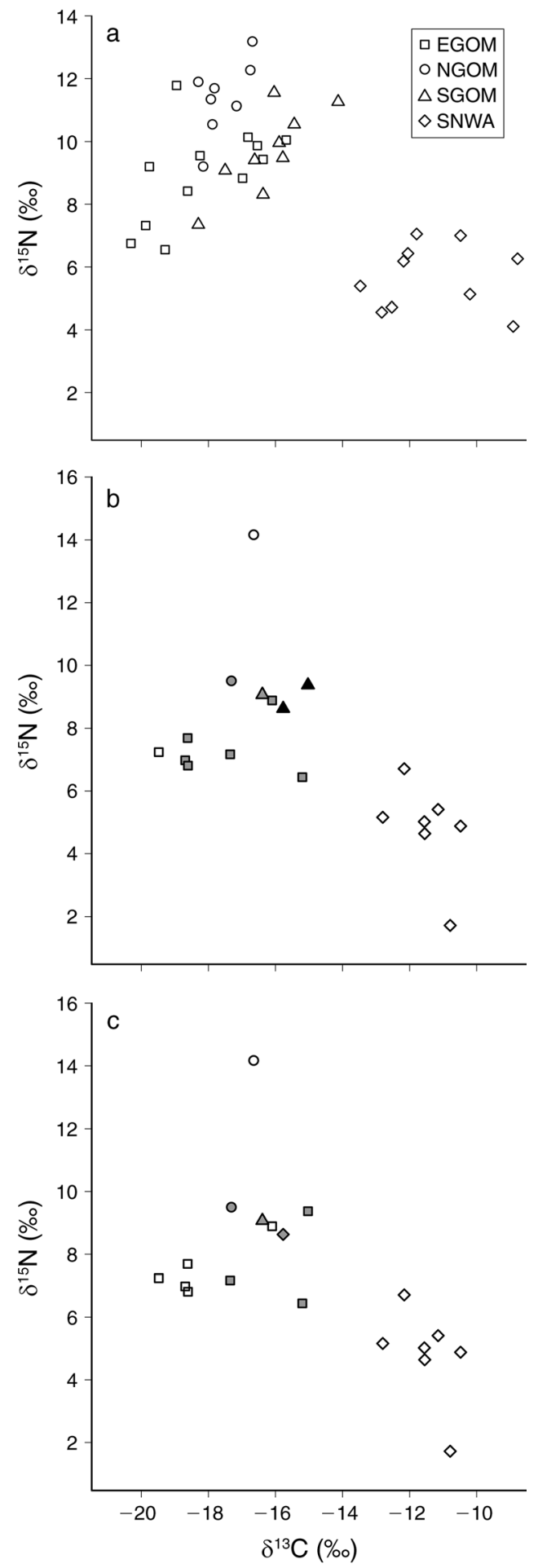

FIG. 2. Nominal assignment of loggerhead turtles to a foraging area. Carbon and nitrogen isotope values of (a) the calibration data set ( $n=39$ turtles) with known foraging area and the validation data set ( $n=19$ turtles) with the assigned foraging areas determined through discriminant analysis using (b) uniform priors or (c) nonuniform priors. Validation individuals that could not be assigned with a probability of group membership $\geq 0.8$ are plotted with gray symbols that indicate the known foraging area as determined through
TABle 3. Posthoc Tukey HSD results comparing stable isotope values in loggerheads among four foraging areas.

\begin{tabular}{ccccc}
\hline \hline & \multicolumn{4}{c}{ Foraging area } \\
\cline { 2 - 5 } Foraging area & EGoM & NGoM & SGoM & SNWA \\
\hline EGoM & & 0.82 & $\mathbf{0 . 0 2}$ & $<\mathbf{0 . 0 0 1}$ \\
NGoM & $\mathbf{0 . 0 0 1}$ & & 0.19 & $<\mathbf{0 . 0 0 1}$ \\
SGoM & 0.65 & $\mathbf{0 . 0 4}$ & & $<\mathbf{0 . 0 0 1}$ \\
SNWA & $<\mathbf{0 . 0 0 1}$ & $<0.001$ & $<\mathbf{0 . 0 0 1}$ & \\
\hline
\end{tabular}

Notes: Comparisons of $\delta^{13} \mathrm{C}$ values are reported in the cells above the diagonal, while comparisons of $\delta^{15} \mathrm{~N}$ values are below the diagonal with significant differences in bold. The SAB (South Atlantic Bight) was not included in this analysis as a result of the small sample size. Foraging areas are EGoM, Eastern Gulf of Mexico; NGoM, Northern Gulf of Mexico; SGoM, Southern Gulf of Mexico; SWNA, Subtropical Northwest Atlantic.

foraging area boundaries in the continuous surface approach, we cannot assess the accuracy for classification in or out of the GoM.

Using nonuniform priors, the accuracy remained the same $(79 \%)$ at the selected threshold (Fig. 3, Table 4). Again, restricting the evaluation to only the 13 individuals that could be assigned in the nominal approach with nonuniform priors, the accuracy was $84 \%$ (11 of 13 individuals were assigned correctly).

Individual binary assignments were summed to identify hotspots of foraging area use at the population level with uniform and nonuniform priors (Fig. 4). Both summaries depict concentrated areas of foraging in the EGoM and SNWA, to which the majority of validation individuals had been tracked.

Less stringent thresholds resulted in increased accuracy with reduced precision (i.e., more area selected as "likely") with the opposite occurring for more stringent thresholds (Fig. 3). Across the range of thresholds, there was very little difference in accuracy between using uniform or nonuniform priors. However, at lower thresholds, the nonuniform priors were slightly more accurate. In order to assign all validation individuals with $100 \%$ accuracy with uniform priors, the threshold would need to be lowered to 0.2 , thus excluding only $20 \%$ of the study domain in the area of likely origin. With nonuniform priors, all validation individuals were assigned with $100 \%$ accuracy at a threshold of 0.46 , thus excluding $46 \%$ of the study domain.

\section{DisCUSSION}

We have demonstrated that stable isotope values in scute tissue can be used to predict foraging area origin for loggerheads in the GoM. Both methodological

satellite tracking. Validation individuals that were assigned incorrectly (only in b) are plotted with solid, black symbols. See Table 4 for assignment accuracy using this method. Foraging areas are EGoM, Eastern Gulf of Mexico; NGoM, Northern Gulf of Mexico; SGoM, Southern Gulf of Mexico; SNWA, Subtropical Northwest Atlantic. 
TABlE 4. Assignment conducted using nominal and continuous-surface approaches for 19 validation individuals with uniform and nonuniform priors.

\begin{tabular}{lccccc}
\hline \hline \multirow{2}{*}{ Approach } & \multicolumn{2}{c}{ Total assignment } & & \multicolumn{2}{c}{ Assignment accuracy } \\
\cline { 2 - 3 } \cline { 5 - 6 } \cline { 5 - 6 } Nominal & Uniform priors & Nonuniform priors & & Uniform priors & Nonuniform priors \\
\hline Continuous & $58 \%(11 / 19)$ & $68 \%(13 / 19)$ & & $82 \%(9 / 11)$ & $100 \%(13 / 13)$ \\
& $100 \%(19 / 19)$ & $100 \%(19 / 19)$ & & $79 \%(15 / 19)$ & $79 \%(15 / 19)$ \\
\hline
\end{tabular}

Notes: The total assignment and assignment accuracy rates were calculated for each approach as a percentage. The numbers in parentheses are the ratio of individuals assigned in each category.

approaches resulted in high accuracy of assignment to the correct foraging area. The use of isoscapes has been limited in the marine environment, and we perform the first example of probabilistic assignment to marine $\delta^{13} \mathrm{C}$ and $\delta^{15} \mathrm{~N}$ isoscapes that were created in this study. Our results validate that the isotopic gradients in this top consumer can be used to trace movements between feeding and reproductive areas. Ultimately, these methodological contributions can inform future research. It can be hypothesized that isotopic patterns observed in loggerheads would also be reflected in other marine species in the region. Though this study focused on sea turtles, the approaches used here are applicable to other migratory marine species.

\section{Spatial patterns in stable isotope values}

Using stable isotope analysis to dependably delineate foraging area origin requires geographical variation in

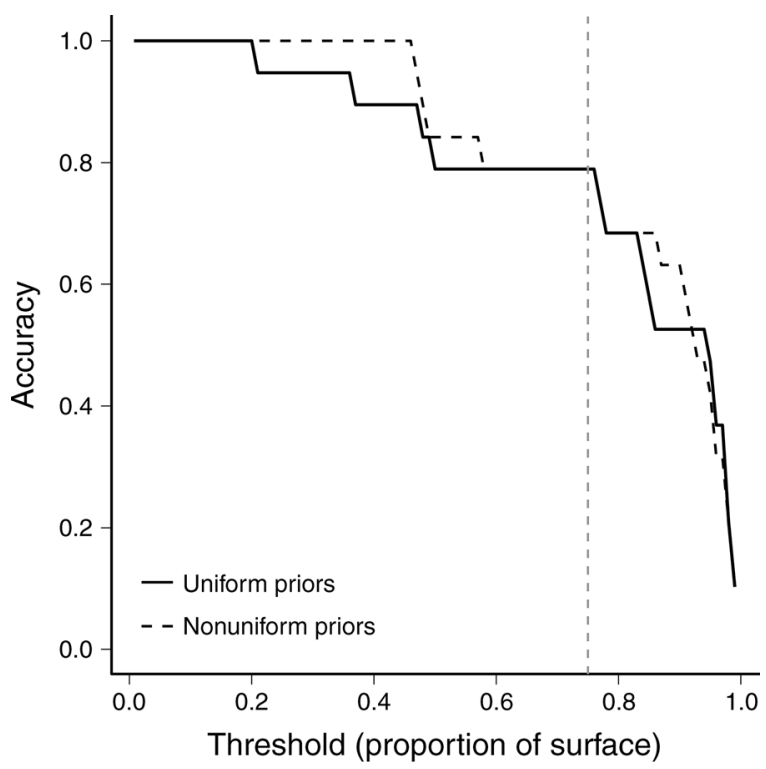

FIG. 3. Assignment accuracy in the continuous-surface approach was measured as the proportion of validation individuals for which the known foraging location was contained within the likelihood surface at a given threshold. Accuracy was examined at a range of thresholds from 0.01 to 0.99 at 0.01 intervals, defined as the proportion of the total possible surface. The dotted vertical line indicates the threshold used in this study for binary classification, where only the upper $25 \%$ of the surface was selected. Accuracy increased at lower thresholds, but the overall accuracy was similar between the use of uniform and nonuniform priors to perform the assignment.
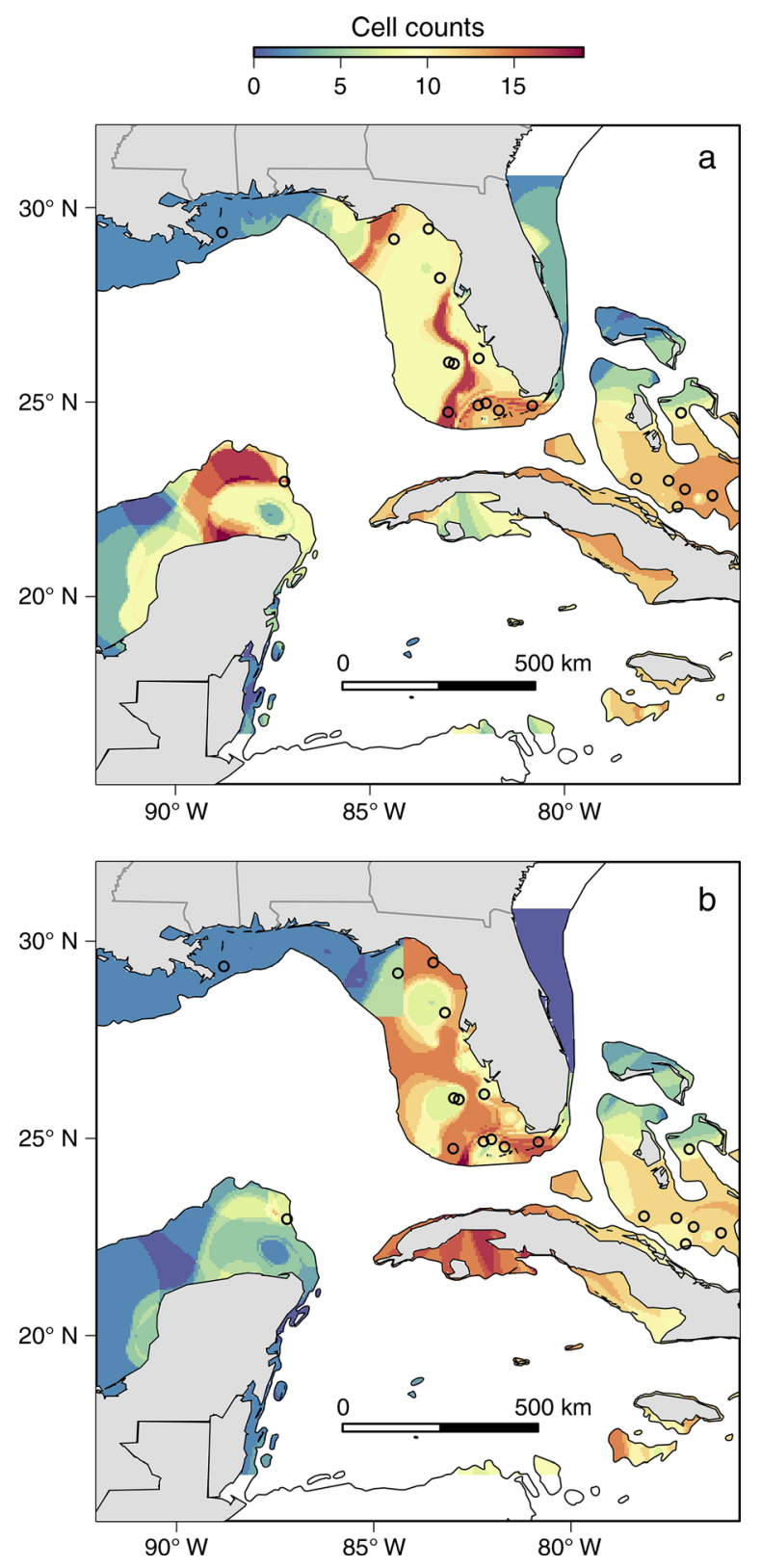

FIG. 4. Geographic distribution of assigned foraging sites as predicted by continuous-surface assignment for loggerheads nesting in the Gulf of Mexico. Validation individual assignment plots were created using (a) uniform and (b) nonuniform priors and were reclassified to binary surfaces using the upper $25 \%$ of posterior probabilities prior to summation. Points represent foraging area centroids as determined through satellite tracking. 
isotopic values among the potential regions used by the population. Significant spatial patterning in $\delta^{13} \mathrm{C}$ and $\delta^{15} \mathrm{~N}$ values of loggerhead scute was observed among the areas studied (Table 3). Similarly, Tucker et al. (2014) found that $\delta^{13} \mathrm{C}, \delta^{15} \mathrm{~N}$, and $\delta^{34} \mathrm{~S}$ values in the epidermis of loggerheads from Casey Key, Florida, were affected primarily by foraging area, irrespective of body size, year sampled, and depth of foraging area as determined by satellite tracking. Creating isoscapes for a continuous-surface assignment approach did not require the delineation of foraging area boundaries as in the nominal assignment. While we attempted to define foraging areas that reflected distinct biological, geological, and isotopic differences for the nominal assignment, the loggerhead-specific isoscapes demonstrate that the isotopic values do not necessarily change abruptly along these lines, but rather change gradually through space (Fig. 1a and b).

We expect that the patterns observed in loggerhead tissue reflect spatial variation at lower trophic levels rather than dietary differences among individuals (Pajuelo et al. 2010, Radabaugh et al. 2013, Vander Zanden et al. 2013). Isoscapes of zooplankton $\delta^{13} \mathrm{C}$ and $\delta^{15} \mathrm{~N}$ values in the Atlantic Ocean depict a region of low $\delta^{15} \mathrm{~N}$ values in zooplankton in the Caribbean (McMahon et al. 2013), similar to the SNWA loggerheads in this study. Conversely, minimal variation was observed for $\delta^{13} \mathrm{C}$ values of zooplankton in the GoM and greater Caribbean (McMahon et al. 2013), despite variation observed in loggerhead tissue. However, these Atlantic Ocean isoscapes do not provide the same spatial resolution as the isoscapes created in this study, and they reflect relatively few sampling events in the GoM (McMahon et al. 2013). Therefore, our isoscapes should be compared to those of McMahon et al. (2013) with caution.

Isoscapes based on fish muscle samples and benthic algae in a smaller region of the GoM (Radabaugh et al. 2013) provide another comparison for the spatial isotopic variation observed in loggerheads. The fish and algae isoscapes reflect a shift from a eutrophic zone in the NGoM with higher $\delta^{15} \mathrm{~N}$ values to mesotrophic and oligotrophic waters in the EGoM (Radabaugh et al. 2013), and similar patterns were observed in the loggerheads in these two regions. The high $\delta^{15} \mathrm{~N}$ values of loggerheads foraging in the NGoM are likely due to the nutrient-rich waters associated with the Mississippi River and possible denitrification associated with low oxygen conditions (Rabalais et al. 1996, Montoya 2007). Nitrogen fixation may drive the low $\delta^{15} \mathrm{~N}$ values in other regions (Macko et al. 1984), particularly in the SNWA.

The $\delta^{13} \mathrm{C}$ patterns in fish and algae in the NGoM and EGoM exhibited inshore-offshore patterns that were correlated with water depth (Radabaugh et al. 2013). We did not relate isotopic values in loggerheads to water depth, but the isotope values changed along an east-west gradient in the EGoM in our study (Fig. 1a and b). This depth gradient may be due to POC and chlorophyll concentrations that support rapid algae growth in shallow, nutrient-rich water, resulting in higher $\delta^{13} \mathrm{C}$ values. Additionally, the high $\delta^{13} \mathrm{C}$ values exhibited by loggerheads foraging in the SNWA are likely a result of seagrass-dominated ecosystems (Vander Zanden et al. 2013), as these primary producers have $\delta^{13} \mathrm{C}$ values that are typically higher than those of phytoplankton, macroalgae, and mangroves (Michener and Kaufman 2007, Bouillon et al. 2008).

It is also possible that these regional patterns may be dynamic as a result of seasonal variability (CallejasJimenez et al. 2012). However, stable isotope values in higher trophic level organisms dampen variation in primary producers between seasons and years, as they incorporate the environmental signal over a longer time period (O'Reilly et al. 2002, Bump et al. 2007). Consistent interannual and seasonal patterns were observed in the fish isoscapes (Radabaugh et al. 2013), indicating the presence of stable spatial gradients in the region. Additionally, because the loggerhead scute tissue represents a time period of approximately $0.6 \mathrm{yr}$ (Vander Zanden et al. 2010), we expect the effect of temporal variation to be minimal.

While we have used scute in our analyses to develop both the nominal and continuous-surface models, we expect that other tissues reflecting a time period on the order of over several months (e.g., epidermis and red blood cells) would demonstrate similar patterns. Rescaling these data to predict origin with other tissues would be possible using appropriate discrimination factors to relate scute to a different tissue of interest (Vander Zanden et al. 2014b).

\section{Nominal vs. continuous-surface assignment}

We tested two methods for determining foraging area origin of nesting loggerheads. Both approaches required samples from known-origin individuals to create predictive models, which was achieved through satellite tracking. Despite the spatial structuring in loggerhead isotope values within the study area, there was some overlap in values among foraging areas, particularly within the GoM (Fig. 2a), which may have contributed to low posterior probabilities in the nominal approach or inaccurate assignments in the continuous-surface approach for some individuals.

Not all of the validation individuals could be assigned using the nominal assignment approach, as the posterior probability was lower than our threshold. Therefore, assignments from up to $42 \%$ of the validation samples (depending on whether or not priors were used) were not considered in this approach. The nominal approach performs better when the regions are isotopically distinct, and can be sensitive to how the regions are defined as well as the threshold used for classification. The threshold selected here ensures a high accuracy of assignment (82-100\%) with the tradeoff that many individuals could not be assigned (Table 4). The accuracy for determining whether individuals originated 
from within or outside of the GoM was very high as a result of the large isotopic differences between these two regions. Therefore, this approach can be most useful for delineating origins from within the GoM vs. the SNWA.

In contrast, the continuous-surface approach allowed all individuals to be considered. In some cases, this method resulted in spatially disjunct areas of likely origin, such that areas of high relative probability spanned portions of multiple defined foraging areas (Appendix C: Figs. C1-C4). Despite being able to ascertain an origin for all individuals in the continuoussurface approach, the proportion assigned correctly was lower than in the nominal assignment, but the total number assigned correctly was greater (Table 4). It is important to note that the incorrect assignments were not extremely inaccurate in most cases, but rather individuals were often close to the borders of the "likely" region of the binary surface (Appendix C: Figs. C3-C4). Nevertheless, there appears to be a trade-off between accuracy and inclusion of all data for the two methods. Continuous-surface assignments can also be used to aggregate individual results to identify hotspots of geographic origin at the population level (Van Wilgenburg and Hobson 2010, Flockhart et al. 2013). In this case, the summary plots provide a valid depiction of the actual distribution of the known foraging sites.

We have selected fairly conservative threshold values for both approaches to ensure high confidence in the resulting assignments, but accuracy levels would change if these thresholds were altered. Researchers and managers must balance the risk of making inaccurate assignments with being able to confidently assign a large portion of the individuals sampled. Use of validation data sets in exploratory studies to examine accuracy across a range of potential thresholds, as we have done here, can aid in selecting appropriate thresholds that balance accuracy and precision for the species and study areas of interest.

\section{Incorporating priors}

We examined the effect of including nonuniform priors related to foraging area distributions to potentially increase assignment accuracy over uniform priors. Royle and Rubenstein (2004) advocate using relative abundance of organisms within the study areas when available, as it may provide more accurate assignments than using the probabilistic assignments alone. We applied nonuniform priors that were specific to each nesting beach based on all previous satellite tracking data available, which are associated with some assumptions. First, we assumed that the proportion of loggerheads originating from distinct foraging areas is constant among years, which may not be the case, as interannual variability in the foraging area proportions has been documented in the Northwest Atlantic (Pajuelo et al. 2012, Vander Zanden et al. $2014 a$ ). Second, we assumed that there is no exchange of turtles among beaches, as the nonuniform priors are specific to each beach. However, the nesting beach fidelity may vary among sites and individuals (Tucker 2010, Hart et al. 2013). Finally, others wishing to replicate our approach would be disadvantaged if this type of tracking information were not available for the rookery of interest.

The use of nonuniform priors in the nominal assignment increased the number of assignments meeting the probability threshold as well as the accuracy of assignments, but the accuracy did not change in the continuous-surface assignments. Three of the four inaccurate continuous-surface assignments were the same with and without nonuniform priors (Appendix C: Figs. C3 and C4). Therefore, it appears that some individuals do not have stable isotope values that correlate with the predicted values for their foraging site. This might be a result of individual variation in physiology in how the stable isotopes are incorporated through the diet and assimilated into the tissue (Barnes et al. 2008, Vander Zanden et al. 2012). On the other hand, using the foraging site centroid may present a limited perspective of the home range, as foraging areas for loggerheads have been demonstrated to range over $1000 \mathrm{~km}^{2}$ (Marcovaldi et al. 2010, Foley et al. 2014), and the centroids of the inaccurate classifications were often near the edges of the binary continuous-surface assignments.

\section{Applications to management}

The spatial distribution in stable isotope values of loggerheads in and around the GoM was advantageous for assessing foraging area origin. We expect that stable isotope values in other marine organisms would also be distributed similarly, thus providing a promising method for tracking migratory movements of other species in this region. Both assignment approaches can be used in future studies to determine the foraging area of untracked individuals in this region with high accuracy. Regular monitoring of sea turtle nesting populations with stable isotope analysis can be used to detect trends in abundance in foraging areas from the nesting beach (Vander Zanden et al. 2014a) and potentially allow for more effective determination of the causes for increasing or decreasing population trends. Additionally, foraging area preference has been linked to reproductive output for many loggerhead populations (Zbinden et al. 2011, Hatase et al. 2013, Cardona et al. 2014, Vander Zanden et al. 2014a), and thus determining foraging area distributions within a nesting aggregation can provide improved demographic estimates. Finally, knowledge about the movements and foraging patterns of these understudied populations can be useful for identifying potential threats that are not geospatially homogenous. Interactions with commercial fisheries have been identified as the primary contributor to declining loggerhead populations in Florida (Witherington et al. 2009), and petroleum activities present new and serious threats as well (Hart et al. 2013). For example, areas of high use by sea turtles can be compared to fisheries efforts or active oil and gas platform maps (Hart et al. 2013, 2014, Hardy et al. 2014), and the spatial overlap of foraging areas with the effects from catastrophic events such as the 
Deepwater Horizon oil spill could be better predicted in the future.

Depending on the goals and applications for determining foraging area, one approach may be more suitable than the other. When defined boundaries (e.g., management units or countries of jurisdiction) are necessary for determining foraging area origin, the nominal approach will be more appropriate. The use of nonuniform priors is recommended, but the disadvantage of this approach is that there will likely be a portion of the population for which the foraging area cannot be determined. Nominal assignment was extremely accurate in determining habitat use in or out of the GoM, which may be helpful to identify individuals that could be susceptible to threats within the GoM. For applications when boundaries are not necessary, the continuous-surface approach may be more appropriate. In this approach, assignment with the use of uniform priors was equally accurate compared to assignment with nonuniform priors at the threshold employed in this study, which can be advantageous when extensive satellite tracking data are not available to generate nonuniform priors. However, use of nonuniform priors may be more informative in other regions or species. Whereas all individuals can be assigned using this method, the disadvantage is that a slightly reduced accuracy rate was observed in comparison to nominal assignment. Additionally, the continuous-surface approach provides the ability to depict population-level summaries, and thus, individual-level assignments can be amalgamated to identify spatially explicit regions of concentrated foraging area use.

It should also be noted that we did not include the $\mathrm{SAB}$ as a potential foraging region in the nominal assignment on the basis that this region was only used by a small portion of the loggerheads in the study ( 2 of $60)$. For nesting aggregations that have a higher percentage of individuals originating from the SAB, including this region in a nominal assignment approach could present lower assignment success, as loggerheads using this area are isotopically similar to those from the EGoM (Pajuelo et al. 2012), and the probability of group membership would likely be split between the two. Consequently, for nesting aggregations in which individuals potentially originate from both the EGoM and SAB foraging areas, the continuous-surface approach would be more suitable.

Satellite tracking will continue to be useful when identifying migratory pathways is necessary, but combinations of other types of data with the $\delta^{13} \mathrm{C}$ and $\delta^{15} \mathrm{~N}$ values may improve foraging area assignment accuracy and precision in future studies. Sulfur stable isotope values $\left(\delta^{34} \mathrm{~S}\right)$ can reflect differences in inshore-offshore habitat use (Barros et al. 2010), but may not provide additional resolution when the study population uses only neritic waters. Values of $\delta^{34} \mathrm{~S}$ in epidermis samples from loggerheads nesting in Casey Key, Florida, USA, exhibited few significant differences among foraging areas, and therefore may not be as effective in improving assignment accuracy and precision as other types of data in the GoM (Tucker et al. 2014). Compound-specific stable isotope analysis of amino acids (CSIA-AA) can be used to further investigate the dietary vs. locational variation within regions (Seminoff et al. 2012, Vander Zanden et al. 2013), as different amino acids reflect source vs. trophic processes. Creating isoscapes with compoundspecific isotope data may not be pragmatic due to the cost of this analysis compared to bulk isotope analysis. However, a recent CSIA-AA marine isoscape created from mussel (Mytilus californianus) tissue reflects the baseline $\delta^{15} \mathrm{~N}$ values by phenylalanine (an amino acid that reflects source processes) in this primary consumer (Vokhshoori and McCarthy 2014). Genetic data have been used to greatly improve geographic origin assignment of migratory terrestrial birds, but this approach requires marked genetic structuring within the region of interest (Chabot et al. 2012, Rundel et al. 2013). Expanded sequencing of mitochondrial DNA from loggerheads in the Atlantic and other regions has revealed significant structuring of nesting populations (Shamblin et al. 2014), such that the beaches sampled in this study represent three demographically isolated nesting populations. Finally, other naturally occurring intrinsic markers including trace elements, which have differential geographic distributions, have been useful in tracing marine organism movements, including those of sea turtles (Kunito et al. 2002, Thorrold et al. 2007, Carson et al. 2013, López-Castro et al. 2013).

\section{Conclusions}

Many marine organisms have geographically separated foraging and reproductive areas, which presents challenges in monitoring year-round habitat use and designing effective management strategies. Accurately identifying and reducing threats that may be geographically discontinuous requires knowledge about habitat use and movement at all life stages. We have created novel isoscapes in the region to perform probabilistic assignment to bivariate continuous-surface as an alternative approach to the nominal approach that has been employed previously (Ceriani et al. 2012, Pajuelo et al. 2012, Vander Zanden et al. 2014a). The nominal assignment is advantageous for management applications that require defined boundaries, but the assignments of many individuals were inconclusive, as they did not meet the probability of group membership. On the other hand, the continuous-surface assignment considers all individuals and permitted population-level summaries, but with a slightly reduced accuracy rate compared to the nominal approach. Our comparison of methodological approaches for determining foraging area origin has provided a foundation for future work, and we have validated isotopic gradients in these marine consumers that can be used to effectively determine geographic origin for large numbers of untracked female loggerheads nesting in the GoM. Continued regular monitoring and isotopic sampling can provide insight into the demographic trends and population-wide patterns that 
are lacking within the GoM so that the effects of future threats can be better predicted and mitigated.

\section{ACKNOWLEDGMENTS}

The authors thank J. Curtis for stable isotope analyses; P. Eliazar and T. Kaufman for help with sample preparation; B. Stephens and C. Hackett for sample collection on EAFB and SJP; A. Crowder, T. Selby, M. Cherkiss, A. Daniels, and B. Smith with field work at DRTO; and one anonymous reviewer for comments that improved the manuscript. All sample collection was made in compliance with the University of Florida Institutional Animal Care and Use Committee (IACUC) protocol 201101985, the Florida Fish and Wildlife Conservation Commission permits MTP-016, 094, 155, and 176, USGS IACUC protocol USGS-SESC-2011-05 issued to K. Hart and Dry Tortugas permit DRTO-2012-SCI-0008. This study was funded by a grant awarded from the Sea Turtle Grants Program. The Sea Turtle Grants Program is funded from proceeds from the sale of the Florida Sea Turtle License Plate; learn more at www.helpingseaturtles.org. The deployment of satellite tags and the collection of the scute samples by field staff would not have been possible without the institutional support of the Conservancy of Southwest Florida, Mote Marine Laboratory and U.S. Geological Survey. Any use of trade, product, or firm names is for descriptive purposes only and does not imply endorsement by the U.S. Government.

\section{Literature Cited}

Alibardi, L. 2005. Proliferation in the epidermis of chelonians and growth of the horny scutes. Journal of Morphology 265:52-69.

Antoine, J. 1972. Structure of the Gulf of Mexico. Pages 1-34 in R. Rezak and V. Henry, editors. Contributions on the geological and geophysical oceanography of the Gulf of Mexico. Gulf Publishing, Houston, Texas, USA.

Barnes, C., S. Jennings, N. V. C. Polunin, and J. E. Lancaster. 2008. The importance of quantifying inherent variability when interpreting stable isotope field data. Oecologia 155:227-235.

Barros, N. B., P. H. Ostrom, C. A. Stricker, and R. S. Wells. 2010. Stable isotopes differentiate bottlenose dolphins off west-central Florida. Marine Mammal Science 26:324-336.

Bjorndal, K. A., B. W. Bowen, M. Chaloupka, L. B. Crowder, S. S. Heppell, C. M. Jones, M. E. Lutcavage, D. Policansky, A. R. Solow, and B. E. Witherington. 2011. From crisis to opportunity: better science needed for restoration in the Gulf of Mexico. Science 331:537-538.

Bjorndal, K. A., K. J. Reich, and A. B. Bolten. 2010. Effect of repeated tissue sampling on growth rates of juvenile loggerhead turtles Caretta caretta. Diseases of Aquatic Organisms 88:271-273.

Bolten, A. B. 1999. Techniques for measuring sea turtles. Pages 110-114 in K. L. Eckert, K. A. Bjorndal, A. Abreu-Grobois, and M. Donnelly, editors. Research and management techniques for the conservation of sea turtles. IUCN Marine Turtle Specialist Group, Washington, D.C., USA.

Bonnet, X., D. Bradshaw, and R. Shine. 1998. Capital versus income breeding: an ectothermic perspective. Oikos 83:333342.

Bouillon, S., R. M. Connolly, and S. Y. Lee. 2008. Organic matter exchange and cycling in mangrove ecosystems: recent insights from stable isotope studies. Journal of Sea Research 59:44-58.

Bowen, G. J., L. I. Wassenaar, and K. A. Hobson. 2005. Global application of stable hydrogen and oxygen isotopes to wildlife forensics. Oecologia 143:337-348.

Broderick, A. C., M. S. Coyne, W. J. Fuller, F. Glen, and B. J. Godley. 2007. Fidelity and over-wintering of sea turtles. Proceedings of the Royal Society B 274:1533-1539.

Bump, J. K., K. Fox-Dobbs, J. L. Bada, P. L. Koch, R. O. Peterson, and J. A. Vucetich. 2007. Stable isotopes, ecological integration and environmental change: wolves record atmospheric carbon isotope trend better than tree rings. Proceedings of the Royal Society B 274:2471-2480.

Callejas-Jimenez, M., E. Santamaria-del-Angel, A. GonzalezSilvera, R. Millan-Nuñez, and R. Cajal-Medrano. 2012. Dynamic regionalization of the Gulf of Mexico based on normalized radiances ( $\mathrm{nLw}$ ) derived from MODIS-Aqua. Continental Shelf Research 37:8-14.

Cardona, L., A. Aguilar, and L. Pazos. 2009. Delayed ontogenic dietary shift and high levels of omnivory in green turtles (Chelonia mydas) from the NW coast of Africa. Marine Biology 156:1487-1495.

Cardona, L., et al. 2014. Distribution patterns and foraging ground productivity determine clutch size in Mediterranean loggerhead turtles. Marine Ecology Progress Series 497:229241.

Carson, H. S., P. C. López-Duarte, G. S. Cook, F. J. Fodrie, B. J. Becker, C. DiBacco, and L. A. Levin. 2013. Temporal, spatial, and interspecific variation in geochemical signatures within fish otoliths, bivalve larval shells, and crustacean larvae. Marine Ecology Progress Series 473:133-148.

Ceriani, S. A., J. D. Roth, D. R. Evans, J. F. Weishampel, and L. M. Ehrhart. 2012. Inferring foraging areas of nesting loggerhead turtles using satellite telemetry and stable isotopes. PLoS ONE 7:e45335.

Chabot, A. A., K. A. Hobson, S. L. Van Wilgenburg, G. J. McQuat, and S. C. Lougheed. 2012. Advances in linking wintering migrant birds to their breeding-ground origins using combined analyses of genetic and stable isotope markers. PLoS ONE 7:e43627.

DeNiro, M. J., and S. Epstein. 1978. Influence of diet on the distribution of carbon isotopes in animals. Geochimica et Cosmochimica Acta 42:495-506.

DeNiro, M. J., and S. Epstein. 1981. Influence of diet on the distribution of nitrogen isotopes in animals. Geochimica et Cosmochimica Acta 45:341-351.

Dodd, C. K. 1988. Synopsis of the biological data on the loggerhead sea turtle. Caretta (Linnaeus 1758). Biological Report 88(14). Department of Interior, U.S. Fish and Wild Services, Washington, D.C., USA.

Eder, E., A. Ceballos, S. Martins, H. Pérez-García, I. Marn, A. Marco, and L. Cardona. 2012. Foraging dichotomy in loggerhead sea turtles Caretta caretta off northwestern Africa. Marine Ecology Progress Series 470:113-122.

Flockhart, D. T. T., L. I. Wassenaar, T. G. Martin, K. A. Hobson, M. B. Wunder, and D. R. Norris. 2013. Tracking multi-generational colonization of the breeding grounds by monarch butterflies in eastern North America. Proceedings of the Royal Society B 280:20131087.

Foley, A. M., B. A. Schroeder, R. Hardy, S. L. MacPherson, and M. Nicholas. 2014. Long-term behavior at foraging sites of adult female loggerhead sea turtles (Caretta caretta) from three Florida rookeries. Marine Biology 161:1251-1262.

Foley, A. M., B. A. Schroeder, R. Hardy, S. L. MacPherson, M. Nicholas, and M. S. Coyne. 2013. Postnesting migratory behavior of loggerhead sea turtles Caretta caretta from three Florida rookeries. Endangered Species Research 21:129-142.

Girard, C., A. D. Tucker, and B. Calmettes. 2009. Post-nesting migrations of loggerhead sea turtles in the Gulf of Mexico: dispersal in highly dynamic conditions. Marine Biology 156:1827-1839.

Godley, B. J., J. M. Blumenthal, A. C. Broderick, M. S. Coyne, M. H. Godfrey, L. A. Hawkes, and M. J. Witt. 2008. Satellite tracking of sea turtles: where have we been and where do we go next? Endangered Species Research 4:3-22.

Goericke, R., and B. Fry. 1994. Variations of marine plankton $\delta^{13} \mathrm{C}$ with latitude, temperature, and dissolved $\mathrm{CO}_{2}$ in the world ocean. Global Biogeochemical Cycles 8:85-90.

González Carman, V., F. Botto, E. Gaitán, D. Albareda, C. Campagna, and H. Mianzan. 2014. A jellyfish diet for the herbivorous green turtle Chelonia mydas in the temperate SW Atlantic. Marine Biology 161:339-349. 
Graham, B. S., P. L. Koch, S. E. Newsome, K. W. McMahon, and D. Aurioles. 2010. Using isoscapes to trace the movements and foraging behavior of top predators in oceanic ecosystems. Pages 299-318 in J. B. West, G. J. Bowen, T. E. Dawson, and K. P. Tu, editors. Isoscapes: understanding movement, pattern, and process on earth through isotope mapping. Springer, New York, New York, USA.

Gruber, N., C. D. Keeling, R. B. Bacastow, P. R. Guenther, T. J. Lueker, M. Wahlen, H. A. J. Meijer, W. G. Mook, and T. F. Stocker. 1999. Spatiotemporal patterns of carbon-13 in the global surface oceans and the oceanic suess effect. Global Biogeochemical Cycles 13:307-335.

Hardy, R. F., A. D. Tucker, A. M. Foley, B. A. Schroeder, R. J. Giove, and A. B. Meylan. 2014. Spatiotemporal occurrence of loggerhead turtles (Caretta caretta) on the West Florida Shelf and apparent overlap with a commercial fishery. Canadian Journal of Fisheries and Aquatic Sciences 71:1924-1933.

Hart, K. M., and K. D. Hyrenbach. 2009. Satellite telemetry of marine megavertebrates: the coming of age of an experimental science. Endangered Species Research 10:9-20.

Hart, K. M., M. M. Lamont, I. Fujisaki, A. D. Tucker, and R. R. Carthy. 2012. Common coastal foraging areas for loggerheads in the Gulf of Mexico: opportunities for marine conservation. Biological Conservation 145:185-194.

Hart, K. M., M. M. Lamont, A. R. Sartain, and I. Fujisaki. 2014. Migration, foraging, and residency patterns for Northern Gulf loggerheads: implications of local threats and international movements. PLoS ONE 9:e103453.

Hart, K. M., M. M. Lamont, A. R. Sartain, I. Fujisaki, and B. S. Stephens. 2013. Movements and habitat-use of loggerhead sea turtles in the northern Gulf of Mexico during the reproductive period. PLoS ONE 8:e66921.

Hatase, H., K. Omuta, and K. Tsukamoto. 2010. Oceanic residents, neritic migrants: a possible mechanism underlying foraging dichotomy in adult female loggerhead turtles (Caretta caretta). Marine Biology 157:1337-1342.

Hatase, H., K. Omuta, and K. Tsukamoto. 2013. A mechanism that maintains alternative life histories in a loggerhead sea turtle population. Ecology 94:2583-2594.

Hatase, H., K. Sato, M. Yamaguchi, K. Takahashi, and K. Tsukamoto. 2006. Individual variation in feeding habitat use by adult female green sea turtles (Chelonia mydas): are they obligately neritic herbivores? Oecologia 149:52-64.

Hatase, H., N. Takai, Y. Matsuzawa, W. Sakamoto, K. Omuta, K. Goto, N. Arai, and T. Fujiwara. 2002. Size-related differences in feeding habitat use of adult female loggerhead turtles Caretta caretta around Japan determined by stable isotope analyses and satellite telemetry. Marine Ecology Progress Series 233:273-281.

Hawkes, L. A., A. C. Broderick, M. S. Coyne, M. H. Godfrey, L. F. Lopez-Jurado, P. Lopez-Suarez, S. E. Merino, N. VaroCruz, and B. J. Godley. 2006. Phenotypically linked dichotomy in sea turtle foraging requires multiple conservation approaches. Current Biology 16:990-995.

Hawkes, L. A., et al. 2011. Home on the range: spatial ecology of loggerhead turtles in Atlantic waters of the USA. Diversity and Distributions 17:624-640.

Hinga, K. R., M. A. Arthur, M. E. Q. Pilson, and D. Whitaker. 1994. Carbon isotope fractionation by marine phytoplankton in culture: the effects of $\mathrm{CO}_{2}$ concentration, $\mathrm{pH}$, temperature, and species. Global Biogeochemical Cycles 8:91-102.

Hobson, K. A., R. Barnett-Johnson, and T. Cerling. 2010. Using isoscapes to track animal migration. Pages 273-298 in J. B. West, G. J. Bowen, T. E. Dawson, and K. P. Tu, editors. Isoscapes: understanding movement, pattern, and process on earth through isotope mapping. Springer, New York, New York, USA

Hobson, K. A., and L. I. Wassenaar, editors. 2008. Tracking animal migration with stable isotopes. Elsevier, Amsterdam, The Netherlands.

Hobson, K. A., M. B. Wunder, S. L. Van Wilgenburg, R. G. Clark, and L. I. Wassenaar. 2009. A method for investigating population declines of migratory birds using stable isotopes: origins of harvested lesser scaup in North America. PLoS ONE 4:e7915.

Knick, S. T., M. Leu, J. T. Rotenberry, S. E. Hanser, and K. A. Fesenmyer. 2014. Diffuse migratory connectivity in two species of shrubland birds: evidence from stable isotopes. Oecologia 174:595-608.

Kunito, T., I. Watanabe, G. Yasunaga, Y. Fujise, and S. Tanabe. 2002. Using trace elements in skin to discriminate the populations of minke whales in southern hemisphere. Marine Environmental Research 53:175-197.

Lemons, G., R. L. Lewison, L. Komoroske, A. Gaos, C. T. Lai, P. Dutton, T. Eguchi, R. LeRoux, and J. A. Seminoff. 2011. Trophic ecology of green sea turtles in a highly urbanized bay: insights from stable isotopes and mixing models. Journal of Experimental Marine Biology and Ecology 405:25-32.

López-Castro, M. C., K. A. Bjorndal, G. D. Kamenov, R. Zenil-Ferguson, and A. B. Bolten. 2013. Sea turtle population structure and connections between oceanic and neritic foraging areas in the Atlantic revealed through trace elements. Marine Ecology Progress Series 490:233-246.

Macko, S. A., L. Entzeroth, and P. L. Parker. 1984. Regional differences in nitrogen and carbon isotopes on the continental shelf of the Gulf of Mexico. Naturwissenschaften 71:374-375.

Marcovaldi, M. A., G. G. Lopez, L. S. Soares, E. H. S. M. Lima, J. C. A. Thom, and A. P. Almeida. 2010. Satellitetracking of female loggerhead turtles highlights fidelity behavior in northeastern Brazil. Endangered Species Research 12:263-272.

McMahon, K. W., L. Ling Hamady, and S. R. Thorrold. 2013. A review of ecogeochemistry approaches to estimating movements of marine animals. Limnology and Oceanography 58:697-714.

Michener, R. H., and L. Kaufman. 2007. Stable isotope ratios as tracers in marine food webs: an update. Pages 238-282 in R. Michener and K. Lajtha, editors. Stable isotopes in ecology and environmental science. Blackwell Publishing, Oxford, UK.

Miller, J. D. 1997. Reproduction in sea turtles. Pages 51-82 in P. L. Lutz and J. A. Musick, editors. The biology of sea turtles. CRC Press, Boca Raton, Florida, USA.

Montoya, J. P. 2007. Natural abundance of ${ }^{15} \mathrm{~N}$ in marine planktonic ecosystems. Pages 176-201 in R. Michener and K. Lajtha, editors. Stable isotopes in ecology and environmental science. Blackwell Publishing, Oxford, UK

National Research Council. 2010. Assessment of sea-turtle status and trends: integrating demography and abundance. Committee on the Review of Sea Turtle Population Assessment Methods (Bjorndal KA, chair). National Academies Press, Washington, D.C., USA.

O'Reilly, C. M., R. E. Hecky, A. S. Cohen, and P.-D. Plisnier. 2002. Interpreting stable isotopes in food webs: recognizing the role of time averaging at different trophic levels. Limnology and Oceanography 47:306-309.

Pajuelo, M., K. A. Bjorndal, J. Alfaro-Shigueto, J. A. Seminoff, J. C. Mangel, and A. B. Bolten. 2010. Stable isotope variation in loggerhead turtles reveals Pacific-Atlantic oceanographic differences. Marine Ecology Progress Series 417:277-285.

Pajuelo, M., K. A. Bjorndal, K. J. Reich, H. B. Vander Zanden, L. A. Hawkes, and A. B. Bolten. 2012. Assignment of nesting loggerhead turtles to their foraging areas in the Northwest Atlantic using stable isotopes. Ecosphere 3:art89.

Phillips, K. 2011. Beyond the beach: population trends and foraging site selection of a Florida loggerhead nesting assemblage. Thesis. University of Miami, Miami, Florida, USA.

Plot, V., T. Jenkins, J.-P. Robin, S. Fossette, and J.-Y. Georges. 2013. Leatherback turtles are capital breeders: morphometric and physiological evidence from longitudinal monitoring. Physiological and Biochemical Zoology 86:385-397.

R Development Core Team. 2013. R: A language and environment for statistical computing. R Foundation for Statistical Computing, Vienna, Austria. www.r-project.org 
Rabalais, N. N., R. E. Turner, D. Justić, Q. Dortch, W. J. Wiseman, and B. K. S. Gupta. 1996. Nutrient changes in the Mississippi River and system responses on the adjacent continental shelf. Estuaries 19:386-407.

Radabaugh, K. R., D. J. Hollander, and E. B. Peebles. 2013. Seasonal $\delta^{13} \mathrm{C}$ and $\delta^{15} \mathrm{~N}$ isoscapes of fish populations along a continental shelf trophic gradient. Continental Shelf Research 68:112-122.

Ramos, R., and J. González-Solís. 2012. Trace me if you can: the use of intrinsic biogeochemical markers in marine top predators. Frontiers in Ecology and the Environment 10:258-266.

Reich, K. J., K. A. Bjorndal, and A. B. Bolten. 2007. The "lost years" of green turtles: using stable isotopes to study cryptic lifestages. Biology Letters 3:712-714.

Royle, A. J., and D. R. Rubenstein. 2004. The role of species abundance in determining breeding origins of migratory birds with stable isotopes. Ecological Applications 14:1780-1788.

Rundel, C. W., et al. 2013. Novel statistical methods for integrating genetic and stable isotope data to infer individuallevel migratory connectivity. Molecular Ecology 22:4163-4176.

Rushing, C. S., T. B. Ryder, J. F. Saracco, and P. P. Marra. 2013. Assessing migratory connectivity for a long-distance migratory bird using multiple intrinsic markers. Ecological Applications 24:445-456.

Schroeder, B. A., A. M. Foley, and D. A. Bagley. 2003. Nesting patterns, reproductive migrations, and adult foraging areas of loggerhead turtles. Pages 114-124 in B. E. Witherington and A. B. Bolten, editors. Loggerhead sea turtles. Smithsonian Institution, Washington, D.C., USA.

Seminoff, J. A., S. R. Benson, K. E. Arthur, T. Eguchi, P. H. Dutton, R. F. Tapilatu, and B. N. Popp. 2012. Stable isotope tracking of endangered sea turtles: validation with satellite telemetry and $\delta^{15} \mathrm{~N}$ analysis of amino acids. PLoS ONE 7:e37403.

Shamblin, B. M., et al. 2014. Geographic patterns of genetic variation in a broadly distributed marine vertebrate: new insights into loggerhead turtle stock structure from expanded mitochondrial DNA sequences. PLoS ONE 9:e85956.

Somes, C. J., A. Schmittner, E. D. Galbraith, M. F. Lehmann, M. A. Altabet, J. P. Montoya, R. M. Letelier, A. C. Mix, A. Bourbonnais, and M. Eby. 2010. Simulating the global distribution of nitrogen isotopes in the ocean. Global Biogeochemical Cycles 24:GB4019.

Thorrold, S., D. Zacherl, and L. Levin. 2007. Population connectivity and larval dispersal using geochemical signatures in calcified structures. Oceanography 20:80-89.

Tucker, A. D. 2010. Nest site fidelity and clutch frequency of loggerhead turtles are better elucidated by satellite telemetry than by nocturnal tagging efforts: implications for stock estimation. Journal of Experimental Marine Biology and Ecology 383:48-55.

Tucker, A. D., B. D. MacDonald, and J. A. Seminoff. 2014. Foraging site fidelity and stable isotope values of loggerhead turtles tracked in the Gulf of Mexico and Northwest Caribbean. Marine Ecology Progress Series 502:267-279.

Van Wilgenburg, S. L., and K. A. Hobson. 2010. Combining stable-isotope $(\delta \mathrm{D})$ and band recovery data to improve probabilistic assignment of migratory birds to origin. Ecological Applications 21:1340-1351.

Vander Zanden, H. B., K. E. Arthur, A. B. Bolten, B. N. Popp, C. J. Lagueux, E. Harrison, C. L. Campbell, and K. A. Bjorndal. 2013. Trophic ecology of a green turtle breeding population. Marine Ecology Progress Series 476:237-249.
Vander Zanden, H. B., K. A. Bjorndal, W. Mustin, J. M. Ponciano, and A. B. Bolten. 2012. Inherent variation in stable isotope values and discrimination factors in two life stages of green turtles. Physiological and Biochemical Zoology 85:431-441.

Vander Zanden, H. B., K. A. Bjorndal, K. J. Reich, and A. B. Bolten. 2010. Individual specialists in a generalist population: results from a long-term stable isotope series. Biology Letters 6:711-714.

Vander Zanden, H. B., J. B. Pfaller, K. J. Reich, M. Pajuelo, A. B. Bolten, K. L. Williams, M. G. Frick, B. M. Shamblin, C. J. Nairn, and K. A. Bjorndal. 2014a. Foraging areas differentially affect reproductive output and interpretation of trends in abundance of loggerhead turtles. Marine Biology 161:585-598

Vander Zanden, H. B., A. D. Tucker, A. B. Bolten, K. J. Reich, and K. A. Bjorndal. 2014b. Stable isotopic comparison between loggerhead sea turtle tissues. Rapid Communications in Mass Spectrometry 28:2059-2064.

Vander Zanden, H. B., M. B. Wunder, K. A. Hobson, S. L. Van Wilgenburg, L. I. Wassenaar, J. M. Welker, and G. J. Bowen. 2014c. Contrasting assignment of migratory organisms to geographic origins using long-term versus yearspecific precipitation isotope maps. Methods in Ecology and Evolution 5:891-900.

Vokhshoori, N. L., and M. D. McCarthy. 2014. Compoundspecific $\delta^{15} \mathrm{~N}$ amino acid measurements in littoral mussels in the California upwelling ecosystem: a new approach to generating baseline $\delta^{15} \mathrm{~N}$ isoscapes for coastal ecosystems. PLoS ONE 9:e98087.

West, J. B., G. J. Bowen, and T. E. Dawson. 2010. Isoscapes: understanding movement, pattern, and process on Earth through isotope mapping. Springer, New York, New York, USA.

Wilkinson, T. A., E. B. Wiken, J. B. Creel, T. F. Hourigan, T. Agardy, H. Herrmann, L. Janishevski, C. J. Madden, L. E. Morgan, and M. Padilla. 2009. Marine ecoregions of North America. Commission for Environmental Cooperation, Montreal, Quebec, Canada.

Williams, N. C., K. A. Bjorndal, M. M. Lamont, and R. R. Carthy. 2014. Winter diets of immature green turtles (Chelonia mydas) on a northern feeding ground: integrating stomach contents and stable isotope analyses. Estuaries and Coasts 37:986-994.

Witherington, B., P. Kubilis, B. Brost, and A. Meylan. 2009. Decreasing annual nest counts in a globally important loggerhead sea turtle population. Ecological Applications 19:30-54.

Wunder, M. B. 2010. Using isoscapes to model probability surfaces for determining geographic origins. Pages 251-270 in J. B. West, G. J. Bowen, T. E. Dawson, and K. P. Tu, editors. Isoscapes: understanding movement, pattern, and process on earth through isotope mapping. Springer, New York, New York, USA.

Wunder, M. B. 2012. Determining geographic patterns of migration and dispersal using stable isotopes in keratins. Journal of Mammalogy 93:360-367.

Zbinden, J. A., S. Bearhop, P. Bradshaw, B. Gill, D. Margaritoulis, J. Newton, and B. J. Godley. 2011. Migratory dichotomy and associated phenotypic variation in marine turtles revealed by satellite tracking and stable isotope analysis. Marine Ecology Progress Series 421:291-302.

\section{Supplemental Material}

\section{Ecological Archives}

Appendices A-C and a Supplement are available online: http://dx.doi.org/10.1890/14-0581.1.sm 